equivalent to the cost of scanning all stroke patients. It doesn't make sense not to scan stroke patients when the balance of risk and benefit in medicine is so tight.

In 1993 the Stroke Association surveyed all British physicians. ${ }^{14}$ They were asked if they would want computed tomography if they had a stroke; $90 \%$ said "Yes." If the people with most experience of caring for stroke patients would like to have a computed tomography if they had a stroke themselves, why should patients be denied this facility? The evidence for routine use of computed tomography in acute stroke is overwhelming.

1 Donnan GA. Investigation of patients with stroke and transient ischaemic attacks. Lancet 1992;339:473-7.

2 King's Fund Forum Consensus Conference. Treatment of stroke. BMF 1988;297:126-8.

3 Royal College of Physicians of London. Stroke: towards better management. Summary and recommendations. $\mathcal{F} R$ Coll Phys Lond 1990;24:15-7.

4 United States National Stroke Association. Consensus statement. Stroke Clinical Updates 1933;IV(1):1-12.

5 Sandercock P, Molyneux A, Warlow C. Value of computed tomography in patients with stroke: Oxfordshire community stroke project. BMf 1985; patients with
6 Antiplatelet Trialists Collaboration. Collaborative overview of randomised trials of antiplatelet therapy. I. Prevention of death, myocardial infarction, and stroke by prolonged antiplatelet therapy in various categories of patients. $B M$ F 1994;308:81-106

7 European Carotid Surgery Trialists Collaborative Group. MRC European carotid surgery trial: interim results for symptomatic patients with severe $(70-99 \%)$ or with mild $(0-29 \%)$ carotid stenosis. Lancet 1991;337: $1235-43$

8 Laupacis A. Anticoagulants for atrial fibrillation. Lancet 1993;342:1251.

9 Bamford J, Sandercock P, Dennis M, Burn J, Warlow C. Classification and natural history of clinically identifiable subtypes of cerebral infarction. Lancet 1991;337:1521-6.

10 Bamford J, Sandercock P, Dennis M, Burn J, Warlow CP. A prospective study of acute cerebrovascular disease in the community: the Oxfordshire of acure cerebrovascular disease in the community: the Oxfordshire community stroke project 1981-86. 2 . In idence, case fatality rates and overall outcome at one year of cerebral infarction, primary intracerebra haemorrhage and subarachnoid haemorrhage. $f$ Newnl Neurosurg Psychiatry 1990;53:16-22.

11 Allen CMC. Clinical diagnosis of acute stroke syndrome. Qf Med 1983;43 515-23.

12 Pounguarin N, Viriyavejaku IA, Komontri C. Siriraj stroke score and validation study to distinguish supratentorial intracerebral haemorrhage from infaction. BMf 1991;302:1565.

13 Dennis MS, Bamford JM, Molyneux AJ, Warlow CP. Rapid resolution of signs of primary intracerebral haemorrhage in computed tomograms of the brain. $B M \widetilde{F} 1987 ; 295: 379-81$.

14 Lindley RI, Amayo E, Marshall J, Dennis MS, Sandercock PAG, Warlow CP. Stroke Association survey of the hospital care of patients with acute stroke in the UK. Age Ageing 1993;23 (suppl):4.

\title{
Costs outweigh benefits
}

\section{S P Allison}

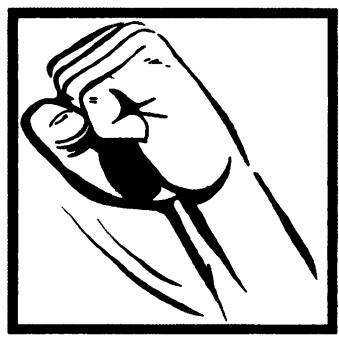

In Britain 100000 strokes occur annually, and patients with stroke occupy a fifth of all medical and a quarter of all long term beds as well as consuming $5 \%$ of the NHS budget. At present half of all acute strokes are managed by general practitioners at home. Last year 891 patients were admitted to the University Hospital, Nottingham, with a diagnosis of stroke; 210 had computed tomography at a cost of $£ 80$ per head. If computed tomography of all patients with stroke became mandatory the first effect would be to double the admission rate to include all those currently managed at home. The additional cost of scanning these and the rest of the 891 patients admitted would be roughly $£ 125000$ a year without the costs of admitting 800 more medical patients. The medicolegal consequences of making computed tomography mandatory in all stroke patients are easily imagined. Computed tomography for stroke must be proved to be extremely effective for such a cost to be justified. I believe that the case has yet to be made.

\section{Reasons for investigation}

Medical investigations can be justified on several counts. In research they can be used to validate a new test against clinical symptoms and signs or against another standard test; to improve understanding of the disease process; or to define patient groups for intervention studies and prospective trials. In clinical practice they are used to define the diagnosis more clearly, allowing more effective and appropriate treatment, and to assist in prognosis.

Comparison of two strategies for management of all United Kingdom strokes in a year $(n=100000)^{\prime}$

\begin{tabular}{lcc}
\hline & $\begin{array}{c}\text { Computed tomography } \\
\text { plus aspirin immediately }\end{array}$ & $\begin{array}{c}\text { Aspirin at } \\
1 \text { month }\end{array}$ \\
\hline Spend $(f)$ & $25 \mathrm{~m}$ & $4 \cdot 4 \mathrm{~m}$ \\
Save $(f)$ & $5 \cdot 7 \mathrm{~m}$ & $4 \mathrm{~m}$ \\
Non-fatal strokes prevented & 285 & 297 \\
Stroke deaths prevented & 142 & 149 \\
Fatal bleeds & 0 & 3 \\
Surgical diagnoses missed & \multicolumn{2}{c}{540} \\
$\quad$ Cerebellar haematoma & \multicolumn{2}{c}{90} \\
Non-vascular disease & & 450 \\
\hline
\end{tabular}

University Hospital,

S P Allison, consultant physician
Computed tomography is currently used to define patient groups for trials of anticoagulant and fibrinolytic drugs. It is used to select patients with thrombotic strokes for treatment and exclude those with haemorrhagic strokes in whom the treatment may be harmful. Ebrahim compared computed tomography and aspirin in the acute phase with aspirin at one month without computed tomography for managing all strokes in Britain in one year (table). ${ }^{1}$ The cost and outcome issues are plain.

\section{Accuracy of clinical diagnosis}

Apart from cases where intervention is pointless, clinicians may be faced with three questions. The first is, has this patient had a stroke or is there another condition? Reports differ concerning the relative value of clinical diagnosis and computed tomography. The sensitivity of the history and examination can be as high as $95 \%$, but specificity varies from $66 \%$ to $97 \%$. ${ }^{23}$ In a recent report from Finland 1191 consecutive patients with a putative diagnosis of stroke were assessed clinically before computed tomography. An expert clinician had a false positive rate of $3 \cdot 1 \%$ and false negative rate of $4.7 \%$ in diagnosing stroke. ${ }^{4}$ Brown et al assessed 821 consecutive admissions to a stroke ward and found that computed tomography did not affect the rate of misdiagnosis. They emphasised the importance of clinical experience in increasing diagnostic accuracy. These reports seem to argue the case for investing in acute stroke units rather than for routine scanning, particularly as such units have been shown to reduce mortality from stroke by $20-30 \%$ without increasing morbidity. ${ }^{6}$

The second question concerns the differentiation between thrombosis and haemorrhage when early antithrombotic treatment is contemplated. Thrombosis and haemorrhage are difficult to differentiate clinically; there is a sensitivity of $68 \%$ and a specificity of $67 \% .^{23}$ But does it matter in terms of treatment? Trials are in progress to determine the role of early treatment, but in the light of current information, delaying aspirin treatment for one month is a reasonable and cost effective strategy. In any case, the computed tomographic appearances of haemorrhage 


\section{Commentary: computed tomography is needed for accurate diagnosis}

Some time ago I was amused to hear a neurologist talking about the enthusiasm of his department to get closer to the "front line" of medicine and emphasising how keen they all were to be contacted when patients with acute neurological problems were admitted to hospital. However, he did add the rider that two conditions were not in his opinion within the realms of acute neurology: one was epilepsy and the other was stroke. This encapsulates the problem since, with a few notable exceptions, no one has regarded stroke as their special interest and the condition is so common that doctors from almost every medical specialty routinely manage patients with stroke. When nothing much could be done other than waiting and seeing it perhaps did not matter about drawing a distinction between cerebral haemorrhage and infarction. But now that aspirin has been shown to be effective in the secondary prevention of cerebral infarction and with many drugs being investigated for treating acute stroke it matters very much. For the foreseeable future most patients with stroke will be managed by doctors who do not specialise in the area. Since even those who are expert cannot reliably distinguish different types of stroke on clinical grounds the case for routine computed tomography seems very strong, and $90 \%$ of British physicians apparently feel the same.PETER C RUBIN, professor of therapeutics, University of Nottingham atrial fibrillation. Primary prevention trials in atrial fibrillation have shown a reduction in stroke or death rate of $67 \%$ with warfarin and $32 \%$ with aspirin. The role of early treatment in secondary prevention remains to be established. Pessin et al described 12 patients who were already receiving warfarin but who suffered embolic infarcts with secondary haemorrhage. $^{8}$ Anticoagulants were continued without ill effects. The case for excluding haemorrhage by computed tomography in such patients is therefore not established.

\section{Summary}

Until the results of early intervention trials are known, computed tomography should be used selectively rather than routinely in all patients with stroke. Scanning may be advised in young patients (under 65 years) or in those with an atypical course where there is diagnostic doubt and computed tomography would influence management. ${ }^{23}$ The cost and medicolegal implications of routine scanning are enormous and should be considered carefully in relation to other and possibly more effective strategies.

and thrombosis are difficult to distinguish after three weeks. The international stroke trial pilot study of aspirin versus low dose heparin within 48 hours of onset suggested that if patients with clinically obvious haemorrhage are excluded-that is, those with severe headache at onset, vomiting, or coma-early and long term mortality was similar in patients who did and did not have computed tomography before beginning treatment.

The third question concerns the differentiation of haemorrhagic from embolic stroke in patients with
1 Ebrahim S. Clinical epidemiology of stroke. Oxford: Oxford University Press, 1990.

2 Royal College of Physicians: Stroke: towards better management. London: RCP, 1990.

3 King's Fund. The treatment of stroke. King's Fund Forum consensus statement. London: King's Fund, 1988.

4 Sotaniemi KA, Pyktinen J, Myllyla VV. Correlation of clinical and computed tomographic findings in stroke patients. Stroke 1990;21:1562-6.

5 Brown M. Cerebrovascular disease. Med Int 1992:99:4158-67.

6 Langhorne P, Williams BO, Gilchrist W, Howie K. Do stroke units save lives?

7 Stroke prevention in atrial fibrillation study: final results. Circulation 1991;84: 527-39.

8 Pessin MS, Estol CJ, Lafranchise F, Caplan LR. Safety of anticoagulation after hemorrhagic infarction. Neurology 1993;43:1298-303. Lancet 1993;342:395-8.

\section{A MEMORABLE PATIENT}

\section{One lady and her dog}

Most of my professional life has involved neurology and more particularly people with epilepsy. I consider myself one of the first of a new breed, at least in Britain: an epileptologist. How did I become interested in epilepsy?

While in medical school, in Brazil, I used to moonlight in the local ambulance service. It was a popular job for medical students, particularly if you wanted to become a surgeon or were simply trying to make ends meet. Although there was supposed to have been comprehensive training, mine consisted of a few on the job stitching sessions during the first couple of weeks from someone two years my senior. After a year of hard shift work in a one in six night and weekend rota in one of the town's first aid stations-the local casualty departments-you would be qualified to apply for a coveted position: spaceship crew or ambulance person. This would not only advance your place in the pecking order among your peers but would also land you with a fatter cheque at the end of the month.

Attending my first call in an ambulance, early one spring night, the dispatcher passed on the message: "Female requesting urgent help at public square." The crew, a driver, a nurse, and myself arrived at the square where we saw a large lady with a barking dog, waving her umbrella, and shouting in a disturbed state: "I am having auras, I am having auras. I am about to have a grand mal attack. I need a diazepam shot now."

I decided to take the matter in hand and announced to my crew and to the audience of perplexed onlookers that we did not have the time to provide drug addicts with a fix. Out of the corner of my eye I could just see the disapproval of the nurse and the driver. They, nevertheless, complied with my instructions and began to move back into the ambulance. Then all hell broke loose. The lady screamed loudly, dropped the dog's lead letting it loose into the crowd, twisted her head, face, and upper half of the body, fell backwards, and started convulsing. I was panic stricken and horrified. I had never seen a convulsion from its onset before, although patients with epilepsy were frequent visitors to the accident and emergency department where I worked. I had just heard about them or seen the aftermath. Against the advice of my experienced associates, who just wanted to give her some diazepam, I decided to take her to the emergency department. I thought that she needed treatment and to be seen by a neurologist. It was a strenuous job in view of her weight to get her on to a stretcher and into the ambulance. We had to enlist the help of several passersby. On the way to hospital she stopped convulsing, was breathing heavily, and was cyanosed. This only increased my disquiet.

Arriving at the hospital she had recovered but was fast asleep. The consultant in charge, well known for his rudeness, was furious at my management. "Sander, you are quite useless. How do you dare to bring an 'epileptic' in, as if we hadn't enough work, especially one who is not fitting. No, there is no way we are getting the on call neurologist to see her. Just get rid of her." Next morning she had fully recovered even if my hurt pride had not. I left a demoralised and tired man. Nevertheless, I went straight to the school's library. I took out as many books on epilepsy as I could. And from there on there was no return.- $\mathrm{J} \mathrm{W}$ A SANDER is an associate specialist in neurology 